\title{
Otimização da Aplicação de Fluazifop-P-Butil em Pós-Emergência na Cultura de Soj a (Glycine max) ${ }^{1}$
}

\author{
Optimizing Fluazifop-P-Butyl Application on Postemergence Soybeans (Glycine max)
}

\author{
LIMA, P.R.F. ${ }^{2}$ e MACHADO-NETO, J.G. ${ }^{3}$
}

\begin{abstract}
RESUMO - O objetivo deste trabalho foi avaliar a possibilidade de redução da dosagem e do volume de calda em função do horário de aplicação do herbicida fluazifop-p-butil em pósemergência na cultura de soja, mantendo-se o controle das plantas daninhas e a seletividade para a cultura. O experimento foi conduzido na área experimental da Fazenda de Ensino e Pesquisa da FCAV/UNESP - Jaboticabal, no ano agrícola 1998/99, na cultura de soja, cultivar FT 2009. O delineamento experimental utilizado foi o de blocos ao acaso com 24 tratamentos, sendo 20 dispostos no esquema fatorial $2 \times 2 \times 5$ e quatro testemunhas. Os fatores testados foram: volume de calda (100 e $200 \mathrm{~L}$ de calda/ha); dosagens reduzidas $-75,2$ e $112,8 \mathrm{~g}$ de fluazifop-p-butil/ha (respectivamente a 40 e $60 \%$ da dosagem recomendada); e horário de aplicação (5, 9, 13, 17 e 21 horas). As testemunhas foram aplicadas com a dosagem recomendada (188,0 g do fluazifop-p-butil/ha) e com os volumes de 100 e $200 \mathrm{~L}$ de calda/ha, no mato (sem controle das plantas daninhas) e "no limpo" (plantas daninhas controladas com enxada manual). As principais espécies de plantas daninhas que emergiram na área experimental foram capim-carrapicho (Cenchrus echinatus), que compunha $60 \%$ da comunidade infestante; capim-colchão (Digitaria horizontalis), 10\%; e capim-pé-de-galinha (Eleusine indica), $30 \%$. Todas as aplicações do herbicida fluazifop-p-butil, nos horários até as 9 horas e a partir das 17 horas, controlaram eficientemente as três espécies de plantas daninhas e foram seletivas para a cultura de soja. Portanto, o uso do herbicida fluazifop-p-butil pode ser otimizado por meio de reduções na dosagem e no volume de calda em aplicações durante os horários com condições ambientais favoráveis à pulverização.
\end{abstract}

Palavras-chave: herbicida, horário de aplicação, redução de dosagem, redução do volume de calda, controle de plantas daninhas.

\begin{abstract}
The objective of this study was to evaluate the possibility of reducing spray concentration and volume of Fluazifop-p-butyl applications on postemergence soybeans, while maintaining weed control and growth selectivity. The study was conducted in the experimental area of the Teaching and Research Farm of FCAV/Unesp - Jaboticabal Campus, during the agricultural season of 1998/99, carried out on a crop of soybean cultivar FT 2009. The experimental setup utilized was a randomized block design with 24 treatments, 20 following a factorial scheme $2 \times 2 \times 5$ and 4 control treatments. The factors examined were: spray volume

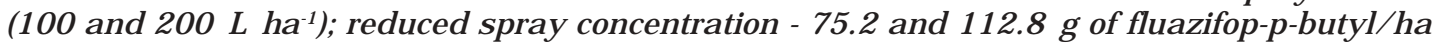
(40 and 60\% of the recommended concentration, respectively); and application schedule (5 A.M., 9 A.M., 1 P.M., 5 P.M. and 9 P.M.). The controls were applications at the recommended

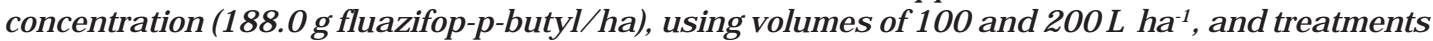
without weed control and weeds controlled with manual hoeing. The main species of weeds that emerged in the experimental area were: Cenchrus echinatus, comprising 60\% of the infested sections; Digitaria horizontalis, 10\%, and Eleusine indica, 30\%. All fluazifop-p-butyl applications made up to 9 A.M. and from 5 P.M. effectively controlled the three species of weeds and provided a selective growth of soybeans. Therefore, the use of fluazifop-p-butyl can be optimized by reducing both the concentration and the volume of the spray for applications times providing favorable conditions for crop dusting.
\end{abstract}

Key words: herbicide, application times, spray concentration reduction, spray volume reduction, weed control.

1 Recebido para publicação em 24 /1/2001 e na forma revisada em 27/3/2001.

Parte da dissertação de mestrado do primeiro autor.

2 Eng.-Agrônomo, mestrando do Programa de Pós-Graduação em Agronomia - área de concentração em Produção Vegetal, da FCAV/UNESP - Jaboticabal; ${ }^{3}$ Prof. Adjunto, Dep. de Fitossanidade FCAV/UNESP - Jaboticabal, Via de Acesso Prof. Paulo Donato Castellane, 14 884-900 Jaboticabal-SP, <joaquim@ @ fcav.unesp.br>.

Planta Daninha, Viçosa-MG, v.19, n.1, p.85-95, 2001 


\section{INTRODUÇÃO}

As perdas de produtividade das culturas devido à interferência das plantas daninhas foram estimadas em torno de $25 \%$ da produção agrícola do País, cuja intensidade depende da densidade das infestações e da época em que estas ocorrem e dos períodos de convivência entre as plantas daninhas e cultivadas. O uso de herbicidas para o controle das plantas daninhas é o método mais eficiente e, especialmente em grandes áreas, o mais econômico (Marochi, 1993).

Entretanto, o controle químico das espécies daninhas em cultura agrícolas deve ser feito aplicando-se os herbicidas em doses mínimas e necessárias para proporcionar períodos de controle suficientes para evitar perdas na quantidade e qualidade do produto colhido (Durigan \& Victória Filho, 1983).

Os herbicidas aplicados em pós-emergência têm sido utilizados na cultura de soja, com grandes vantagens em relação aos residuais. O fator determinante do momento da aplicação em pós-emergência é o estádio de crescimento das plantas daninhas. Nas fases iniciais do ciclo vegetativo, as plantas são mais sensíveis à ação dos herbicidas, e os tecidos jovens os absorvem com maior facilidade (Marochi, 1993).

Controles satisfatórios de plantas daninhas foram obtidos com apenas $25 \%$ das dosagens especificadas nos rótulos de herbicidas aplicados em pós-emergência em estádios iniciais do desenvolvimento das plantas, sob condições favoráveis ao crescimento das plantas e calibração precisa do pulverizador (Baldwin \& Oliver, 1985).

Em aplicações de herbicidas em pós-emergência na cultura da soja, Peressin et al. (1993) verificaram que $80 \%$ da dosagem recomendada de haloxyfop-methyl, quizalofop-ethyl, chlorimuron-ethyl e fomesafen, isolados ou em misturas, proporcionou controles das plantas daninhas similares aos das dosagens recomendadas e não influenciaram a produção da soja.

Esses resultados ocorreram porque as dosagens indicadas nos rótulos das embalagens dos herbicidas são dimensionadas para assegurar controle eficiente das espécies em ampla faixa de condições de manejo e de ambiente (King \& Oliver, 1992). Adotando-se manejo adequado e sob determinadas condições ambientais favoráveis, as dosagens dos herbicidas podem ser reduzidas e proporcionar controle eficiente das plantas daninhas (Devlin et al., 1991).

O herbicida aplicado na folhagem das plantas daninhas não produzirá o efeito desejado se não permanecer na superfície da folha o tempo suficiente para ser absorvido e penetrar internamente. O tempo de permanência das gotas de pulverização que contêm os herbicidas na superfície das folhas depende da ocorrência de características climáticas favoráveis durante e em determinado tempo após a aplicação, sendo os elementos climáticos mais influentes a temperatura e a umidade relativa do ar (Gazziero \& Fleck, 1980).

Condições ambientais favoráveis durante as pulverizações, como menores temperaturas e maiores umidades relativas do ar (Gazziero $\&$ Fleck, 1980) e menores velocidades do vento (Marochi, 1993), favorecem a ação dos herbicidas aplicados em pós-emergência, possibilitando, inclusive, reduções de dosagens e dos volumes de aplicação (Ferreira et al., 1998). As menores temperaturas e maiores umidades relativas do ar ocorrem durante o período noturno (Muzik, 1976). Assim, verifica-se que durante a noite ocorrem as melhores condições ambientais para as aplicações desses herbicidas, possibilitando a redução de dosagens e do volume de calda aplicada.

Friesen \& Wall (1991) aplicaram fluazifopp-butil na cultura de linho para controle das plantas daninhas em pós-emergência, a intervalos de duas horas, no período das 5 às 23 horas, e verificaram que os melhores controles de Setaria viridis ocorreram nas aplicações feitas entre 17 e 23 horas.

Considerando que os horários de aplicação interferem na eficiência dos herbicidas, Marochi (1993) estudou o controle de Brachiaria plantaginea, no estádio de 4 folhas a 1 perfilho, com os herbicidas atrazine $\left(2.400,0 \mathrm{~g} \mathrm{ha}^{-1}\right) \mathrm{e}$ nicosulfuron (600 $\left.\mathrm{g} \mathrm{ha}^{-1}\right)$, aplicados em pósemergência às $6,9,12,15,18,21$ e 24 horas, com bico XR 11002, à pressão de $21 \mathrm{lbf} \mathrm{pol}^{-2} \mathrm{e}$ volume de 2001 de calda/ha. Verificou controle satisfatório da planta daninha nas aplicações realizadas nas primeiras horas do dia e após 
as 15 horas (URar $>60 \%$ ). Estas condições ambientais foram as mais favoráveis à maior duração das gotas. Verificou também controles insatisfatórios nas aplicações realizadas no período entre 12 e 15 horas (URar < 50\%). Com base nestes resultados, esse autor afirma que o baixo controle nos horários de aplicação de 12 e 15 horas está relacionado à baixa umidade relativa do ar. Menciona também que, em condições normais de estádio de desenvolvimento, pode-se ainda reduzir a dose dos herbicidas quando houver boas condições climáticas para as pulverizações, mantendo-se a mesma eficiência e com maior economicidade.

Marochi (1993) não verificou diferenças significativas entre as aplicações de herbicidas com 100, 200 e 300 L de calda/ha. Para os herbicidas sistêmicos, constatou tendência de superioridade quando aplicados com $100 \mathrm{~L} \mathrm{ha}^{-1}$, em relação aos demais. Os herbicidas sistêmicos foram mais eficientes que os de ação de contato nas aplicações com os três volumes estudados. Portanto, o autor concluiu que, com a utilização de volumes menores, há melhor aproveitamento das máquinas na propriedade e, em muitos casos, evita-se a compra de novos pulverizadores e tratores.

Souza \& Dornelles (1995) estudaram a influência do volume de calda $(75,150$ e $250 \mathrm{~L} \mathrm{ha}^{-1}$ ) na mistura de herbicidas aplicados em pós-emergência na cultura de soja, onde testaram as misturas de tanque entre o bentazon e os seguintes herbicidas: acifluorfen$\mathrm{Na}$, lactofen, fomesafen, imazethapyr, chlorimuron-ethyl e imazaquin, bem como a mistura de chlorimuron-ethyl com acifluorfen$\mathrm{Na}$. Verificaram que não houve influência do volume de calda no controle de leiteiro (Euphorbia heterophylla) e de guanxuma (Sida sp.). O picão-preto (Bidens pilosa) foi mais bem controlado com os volumes de 75 e $150 \mathrm{~L}$ de calda/ha do que com $250 \mathrm{~L} \mathrm{ha}^{-1}$. Os autores observaram efeitos da variação do volume de calda/ha sobre o crescimento e rendimento da cultura de soja.

Em geral, ainda há poucos trabalhos de pesquisas sobre a otimização das aplicações de herbicidas em pós-emergência nas culturas agrícolas do País. Particularmente na cultura de soja, esses estudos ainda são poucos, e, com o herbicida fluazifop-p-butil, praticamente inexistem.
O mecanismo de ação do fluazifop-p-butil é a inibição da ACCase, que atua na síntese de lipídios. Os herbicidas inibidores da ACCase são conhecidos como graminicidas, sendo aplicados em pós-emergência e em área total e seletivos para culturas dicotiledôneas em geral. Os primeiros sintomas do efeito desses herbicidas em plantas sensiveis são notados inicialmente na região meristemática, onde a síntese de lipídios, para a formação de membranas, é muito intensa. Em gramíneas, os meristemas próximos aos entrenós sofrem descoloração, ficam marrons e desintegram-se. As folhas recém-formadas ficam cloróticas e morrem entre uma e três semanas após o tratamento. As folhas mais desenvolvidas podem adquirir coloração roxa, laranja ou vermelha, confundindose com o sintoma de deficiência de fósforo (Vidal, 1997).

O objetivo deste trabalho foi avaliar a possibilidade de redução da dosagem e do volume de calda em função do horário de aplicação do herbicida fluazifop-p-butil em pós-emergência na cultura de soja, mantendo-se o controle das plantas daninhas e a seletividade para a cultura.

\section{MATERIAL E MÉTODOS}

No ano agrícola 1998/99 foi instalado e conduzido um experimento na área experimental da Fazenda de Ensino e Pesquisa da Faculdade de Ciências Agrárias e Veterinárias, UNESP - Jaboticabal. A área experimental selecionada estava com histórico de alta infestação de gramineas anuais.

O solo da área experimental foi preparado por meio de aração e duas gradagens. A semeadura da soja e a adubação de sulco foram realizadas mecanicamente no dia 21 de dezembro de 1998. As sementes de soja, cultivar FT 2009, foram previamente tratadas com $300 \mathrm{~g} / 100 \mathrm{~kg}$ do fungicida thiram (Rhodiauran). A semeadura foi feita com uma semeadora mecânica tracionada por trator, de seis linhas espaçadas em $34 \mathrm{~cm}$, regulada para depositar 30 sementes por metro de sulco, na profundidade de $3 \mathrm{~cm}$. A adubação foi dosada com base nos resultados da análise química do solo coletado previamente na área.

O delineamento experimental utilizado foi o de blocos ao acaso, com 24 tratamentos e 
quatro repetições. Dos 24 tratamentos, 20 foram dispostos em um esquema fatorial $2 \times 2$ $x 5$ e quatro eram testemunhas. O fatorial utilizado foi composto pelos três fatores testados nos seus respectivos níveis.

Fator A: Volume de aplicação reduzido - 2 níveis $=100$ e $200 \mathrm{~L} \mathrm{ha}^{-1}$.

Fator B: Dosagem reduzida -2 niveis $=75,2$ e $112,8 \mathrm{~g}$ de fluazifop-p-butil (Fusilade $125 \mathrm{CE}$ /ha, correspondendo, respectivamente, a 40 e $60 \%$ da dosagem recomendada e utilizada nos tratamentos testemunhas aplicados.

Fator C: Horário de aplicação - 5 níveis: 5, 9, 13, 17 e 21 horas. Os horários das aplicações foram considerados de acordo com o horário brasileiro de verão.

Os quatro tratamentos testemunhas foram os seguintes: aplicações com a dosagem recomendada de $188 \mathrm{~g} \mathrm{ha}^{-1}$ de fluazifop-p butil, sendo uma com o volume de 100 de calda/ha e outra com 200 (recomendação-padrão da aplicação- Rodrigues \& Almeida, 1995); e os outros dois tratamentos foram testemunhas sem controle das plantas daninhas e controle total com enxada manual.

As parcelas experimentais foram compostas por dez linhas de semeadura com $6 \mathrm{~m}$ de comprimento, perfazendo $20,4 \mathrm{~m}^{2}$ de área total. As avaliações e coletas de dados foram realizadas na área útil das parcelas compostas pelas seis linhas centrais com $4 \mathrm{~m}$ de comprimento, perfazendo $8,2 \mathrm{~m}^{2}$.

Os tratamentos fitossanitários na área experimental foram: uma aplicação de $2.500 \mathrm{~g} \mathrm{ha}^{-1}$ de fomesafen (Flex), na dosagem de 1,0 L ha ${ }^{-1}$, em área total (Rodrigues \& Almeida, 1995), no dia 2 de fevereiro de 1999, para controle das "folhas largas" presentes na área experimental, e uma aplicação de $480 \mathrm{~g}$ de monocrotophos/ha (Nuvacron) para o controle de percevejos.

As aplicações do herbicida foram feitas no dia 19 de janeiro de 1999, 20 dias após a emergência da cultura. Os valores de temperatura, umidade relativa do ar, temperatura do solo e velocidade do vento nos horários das aplicações são apresentados na Figura 1. As plantas de soja estavam no estádio de crescimento $V_{5}$ (5ํㅡó) e a comunidade infestante estava composta pelas espécies de gramíneas capim- carrapicho (compondo 60\% da comunidade infestante) e capim-colchão (30\%), ambas no estádio de 5 a 8 folhas, e capim-pé-de-galinha (10\%), no estádio de 6 a 8 folhas.

Os herbicidas foram aplicados em área total com pulverizador costal de pressão constante de $40 \mathrm{lbf} \mathrm{pol}^{-2}$, mantida por ar comprimido. A barra de aplicação estava com quatro bicos de jato plano (tipo leque), espaçados de 0,5 m entre si, da série 11001 (laranja), para aplicar o volume de $100 \mathrm{~L}$ de calda/ha, e XR 110 02, marca Jacto, para aplicar 200 L.

Nas aplicações às 9 horas, a nebulosidade atmosférica estava em torno de $30 \%$, e durante o dia foi se reduzindo até atingir 5\% às 17 horas. Nesse dia, o solo da área experimental estava úmido. Nas aplicações às 5 e 21 horas as plantas estavam com as folhas molhadas com orvalho.

Durante o ciclo da cultura foram coletados os dados diários de temperatura e umidade relativa do ar e precipitação na Estação Agroclimatológica do Dep. de Ciências Exatas da FCAV/UNESP - Jaboticabal, localizada a $500 \mathrm{~m}$ da área experimental, cujos valores médios mensais estão apresentados na Figura 2 .

O controle das plantas daninhas nas parcelas que receberam a aplicação de fluazifopp-butil foi avaliado por meio da escala de notas atribuídas visualmente, de 0 a $100 \%$, sendo 0 para ausência de controle e 100 para controle total. Essas avaliações foram realizadas aos 8, 15 e 22 dias após as aplicações, atribuindo-se notas de controle para cada uma das três gramineas dominantes.

Os efeitos do fluazifop-p-butil nas plantas de soja foram avaliados visualmente por meio dos sintomas de intoxicação observados nas plantas aos 8, 15 e 22 dias após as aplicações. Essas avaliações foram realizadas utilizandose a escala de notas de intoxicação do EWRC (European Weed Research Council, 1964).

A colheita da soja foi feita no dia 5 de abril de 1999, com as plantas presentes nas áreas úteis das parcelas sendo arrancadas manualmente e contadas, obtendo-se o estande da cultura. Das plantas retiradas de cada parcela foram separadas dez ao acaso, para medida do comprimento da haste principal e da inserção da primeira vagem e contagem do número 
de vagens por planta. Em seguida, as plantas colhidas foram "trilhadas" e as sementes, pesadas. De cada parcela foram retiradas 100 sementes ao acaso, para quantificação da umidade. Estas sementes foram pesadas imediatamente após a separação, secas em estufa a $105^{\circ} \mathrm{C}$ por 48 horas e pesadas novamente, com as umidades sendo corrigidas para $12 \%$, a fim de se estimar a produção de grãos, em kg ha-1.

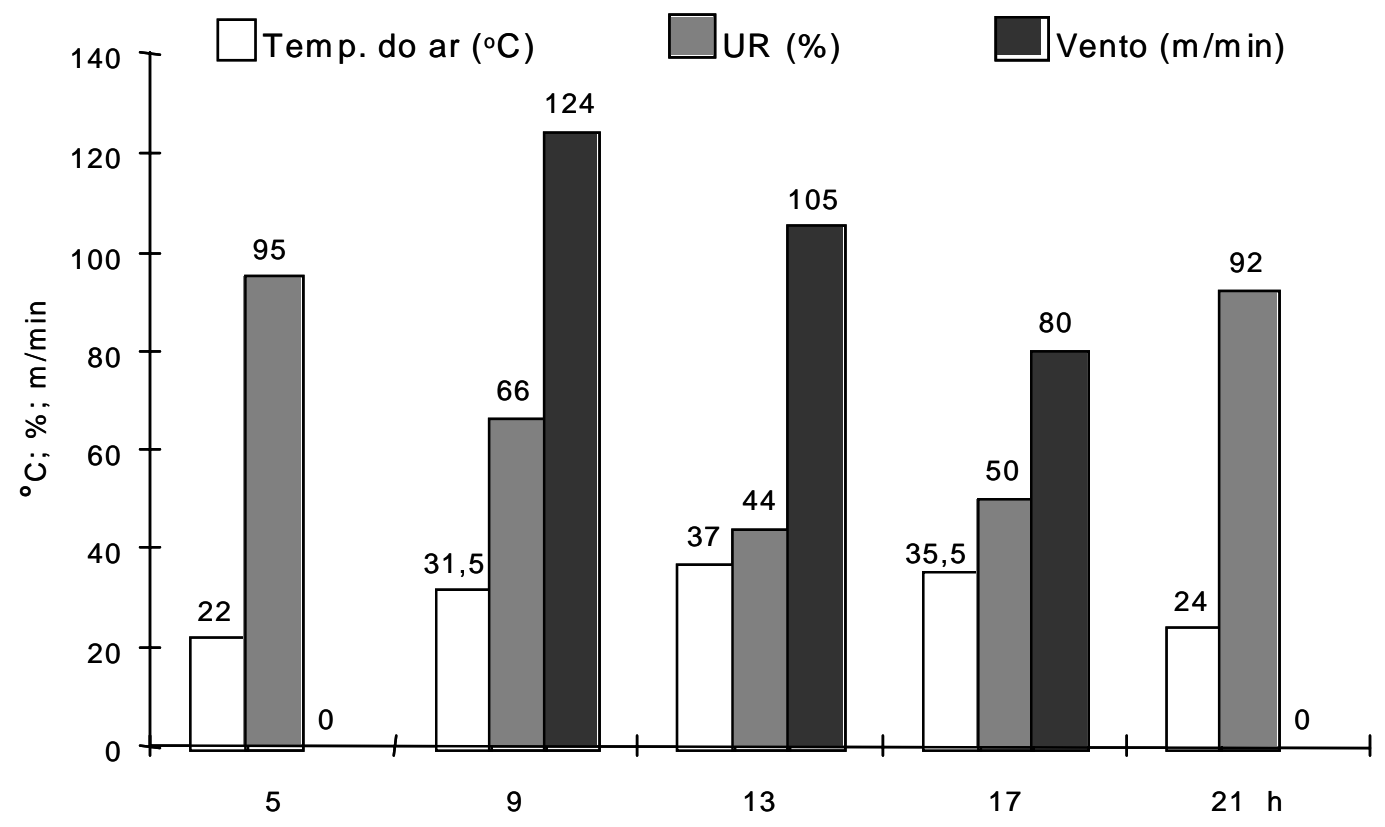

Figura 1 - Valores dos elementos do clima nos horários das aplicações do herbicida fluazifop-p-butil em pós-emergência na cultura de soja. Jaboticabal-SP - 1999.

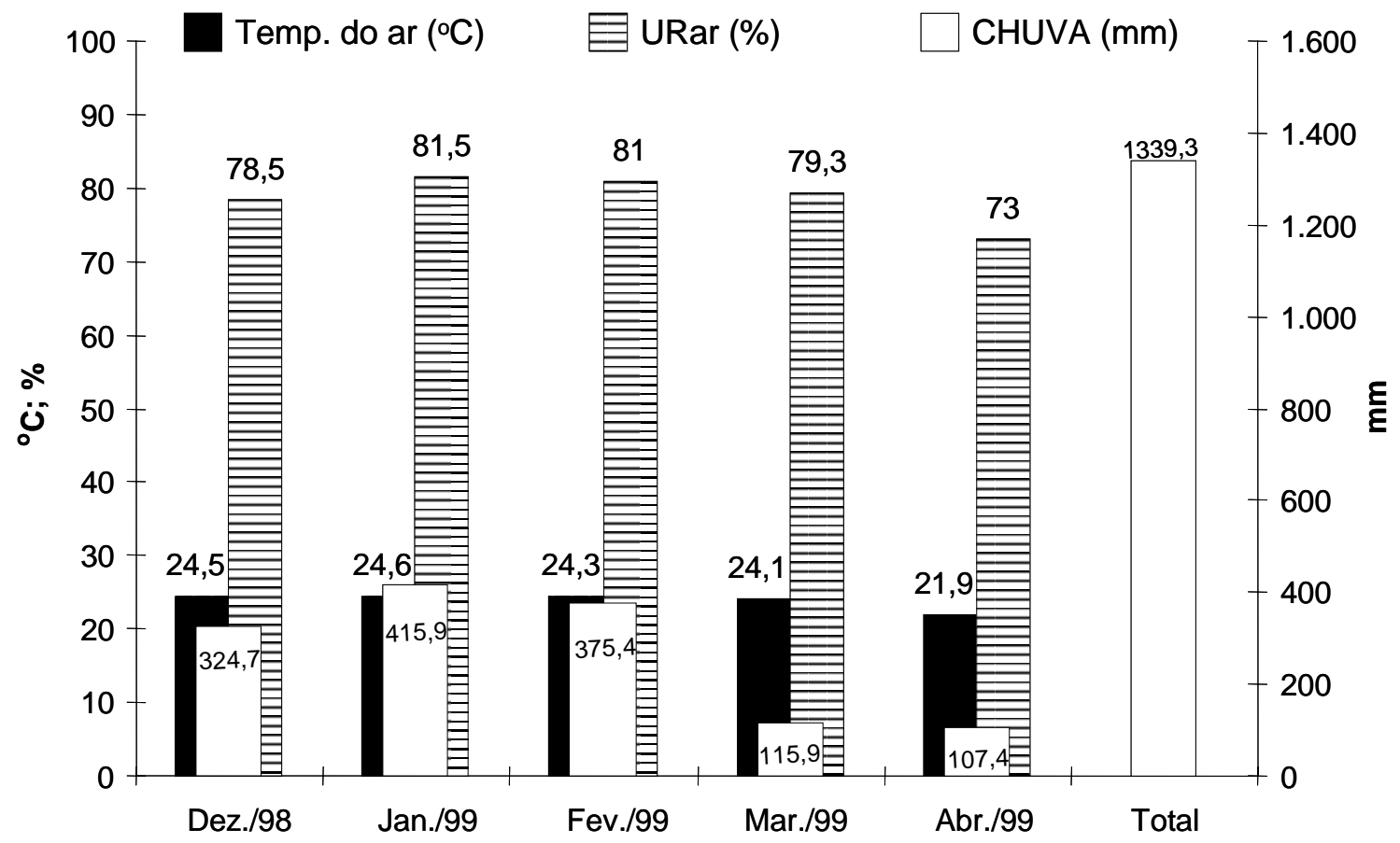

Figura 2 - Valores médios mensais de temperatura e umidade relativa do ar e precipitação durante o ciclo da cultura no campo. Jaboticabal-SP - 1999. 
Os dados experimentais coletados foram analisados estatisticamente pela análise de variância e pelo teste de Tukey, para comparação de médias $(P>0,05)$. Nas análises estatísticas dos dados de controle das plantas daninhas, foram consideradas apenas as duas testemunhas aplicadas com a dose-padrão do herbicida, para comparação com os demais tratamentos. Nas análises estatísticas dos dados obtidos nas avaliações das plantas de soja, foram consideradas as quatro testemunhas.

\section{RESULTADOS E DISCUSSÃO}

A participação das três espécies de gramíneas infestantes dominantes na composição da comunidade infestante, avaliadas nas parcelas do tratamento testemunha sem capina, durante o ciclo da cultura, encontra-se na Figura 3. Verifica-se que as densidades da comunidade infestante permaneceram altas em todas as avaliações. A composição específica das gramíneas dominantes desta comunidade infestante se alterou naturalmente com o decorrer do ciclo da cultura. Aos 8 dias após as aplicações do herbicida a espécie dominante foi o capimcarrapicho, seguido pelo capim-colchão. Essa relação praticamente se manteve nas avaliações aos 15 e 22 dias após as aplicações, embora tenha havido ligeira redução na dominância do capim-carrapicho. Na época da colheita, verificou-se drástica redução da infestação do capim-carrapicho e, praticamente na mesma proporção, aumento da infestação do capimpé-de-galinha, que, por apresentar ciclo mais longo, se tornou a espécie dominante na comunidade infestante.

Os resultados das análises de variância das porcentagens de controles de capim-carrapicho, capim-pé-de-galinha e capim-colchão, nas avaliações aos 8, 15 e 22 dias após as aplicações, estão apresentados na Tabela 1. Verifica-se efeito significativo do fator volume de aplicação aos 8 dias após as aplicações para as três espécies de gramíneas e aos 15 dias apenas para o capim-colchão. O efeito das dosagens reduzidas foi significativo apenas aos 15 dias para o capim-pé-de-galinha. Os horários de aplicação foram significativos nas avaliações de controle das três plantas infestantes, aos 8 e 15 dias.

Planta Daninha, Viçosa-MG, v.19, n.1, p.85-95, 2001
Considerando as interações entre os três fatores, verifica-se que todas foram significativas para o controle de capim-carrapicho aos 8 dias após as aplicações. No controle do capimpé-de-galinha, foram significativas as interações entre volume de aplicação e horário de aplicação aos 8 e 15 dias e entre dosagem reduzida e horário de aplicação apenas aos 8 dias. A interação tripla entre os fatores foi significativa apenas aos 15 dias após as aplicações para o controle das três gramíneas.

Ocorreram diferenças significativas dentro do fatorial nas avaliações de controle das três gramíneas aos 8 e 15 dias após as aplicações, confirmando os efeitos significativos dos fatores isolados (Tabela 1). Da mesma forma, os controles das três gramíneas com os tratamentos do fatorial diferiram significativamente dos controles das testemunhas. Verifica-se também nesses dados que não houve efeito significativo dos fatores isolados aos 22 dias após as aplicações, porque os controles proporcionados pelos tratamentos praticamente se igualaram e foram excelentes (ALAM, 1974), ficando entre 92 e $95,5 \%$.

Considerando as médias gerais dos controles das três gramíneas infestantes dominantes na área experimental (Tabela 1), constata-se a progressão dos controles nas avaliações seqüenciais. Os controles iniciaram-se em torno de $52 \%$ aos 8 dias, evoluíram para 70 a $81 \%$ aos 15 dias e atingiram 92 a $95 \%$ aos 22 dias. A partir desta data e até na época da colheita, verificou-se que estas plantas infestantes praticamente desapareceram das parcelas tratadas.

Os valores médios dos controles e as comparações das interações significativas e diferenciadas pelo teste de Tukey nos desdobramentos dos graus de liberdade dos fatores encontramse nas Tabelas 2 e 3 . Comparando os dados destas tabelas com os valores de F significativos da Tabela 1, verifica-se que nem todos os contrastes com valores de $\mathrm{F}$ significativos foram diferenciados pelo teste de Tukey. Esse fato se deve às pequenas diferenças entre os valores médios dos controles das plantas infestantes, embora os valores de F calculado tenham sido significativos.

Para os fatores isolados, verifica-se que o volume de $100 \mathrm{~L}$ de calda/ha proporcionou controles significativos superiores ao de $200 \mathrm{~L} \mathrm{ha}^{-1}$, 
nas avaliações aos 8 dias após as aplicações para as três espécies de gramíneas e aos 15 dias apenas para o capim-colchão (Tabela 2). Esses resultados estão de acordo com os de Marochi
(1993) e Souza \& Dornelles (1995), em que a redução do volume de aplicação de herbicidas em pós-emergência não prejudicou o controle das plantas infestantes.

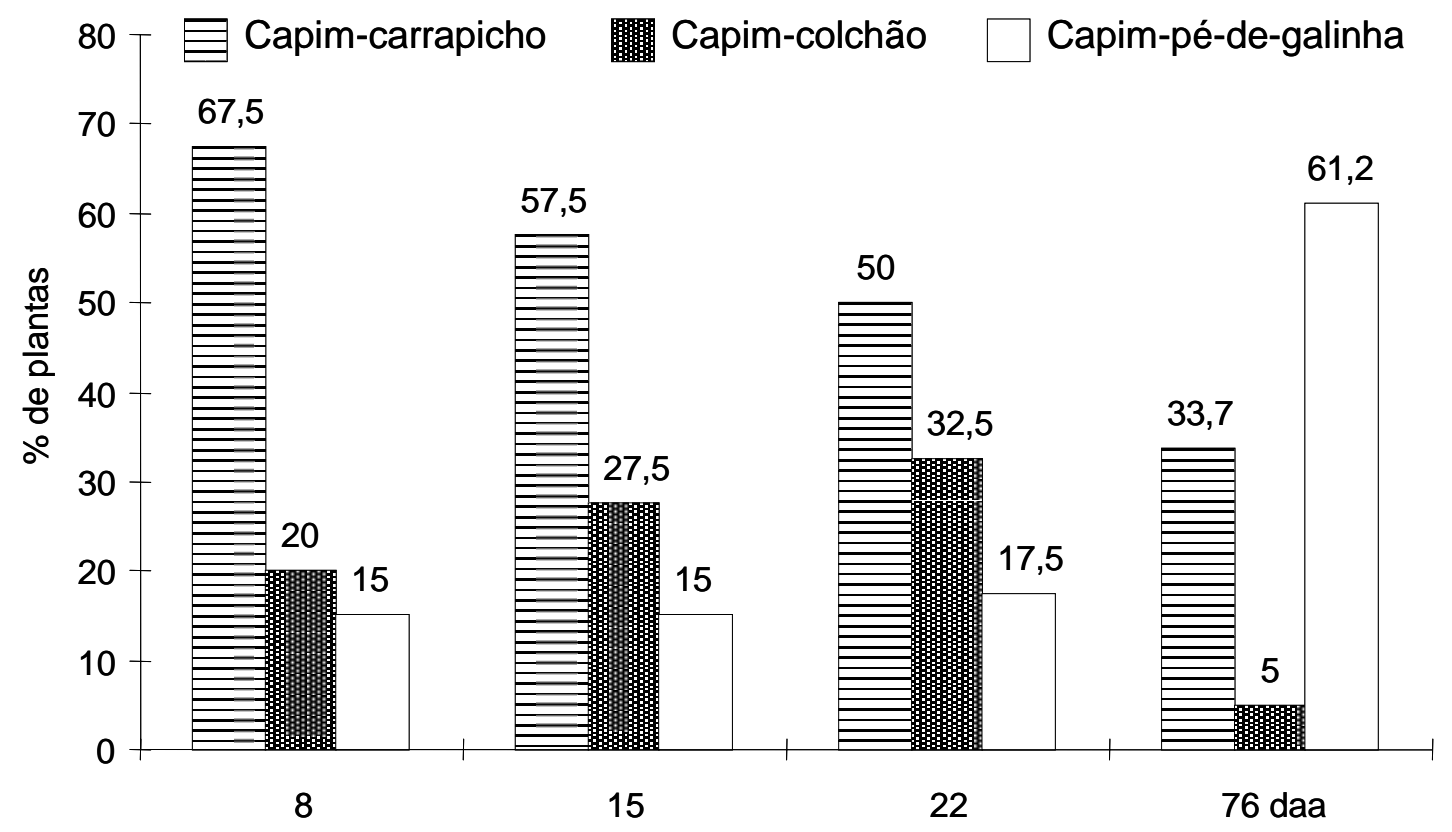

Figura 3 - Valores médios porcentuais da população das três espécies de gramíneas dominantes na comunidade infestante, nas parcelas testemunhas sem capina, na cultura de soja. Jaboticabal-SP - 1999.

Tabela 1 - Valores de F da análise de variância dos dados de controle das plantas infestantes aos 8,15 e 22 dias após as aplicações do herbicida fluazifop-p-butil na cultura de soja. Jaboticabal-SP - 1999

\begin{tabular}{|c|c|c|c|c|c|c|c|c|c|c|}
\hline \multirow{2}{*}{$\begin{array}{c}\text { Causas de } \\
\text { variação }\end{array}$} & \multirow{2}{*}{ GL } & \multicolumn{3}{|c|}{ Capim-carrapicho } & \multicolumn{3}{|c|}{ Capim-pé-de-galinha } & \multicolumn{3}{|c|}{ Capim-colchão } \\
\hline & & $8^{1}$ & 15 & 22 & 8 & 15 & 22 & 8 & 15 & 22 \\
\hline Volume (V) & 1 & $6,99 *$ & 2,32 & 0,91 & $6,99 * *$ & 2,00 & 0,83 & $7,11 * *$ & $7,49 * *$ & 0,21 \\
\hline Dosagem (D) & 1 & 2,13 & 1,61 & 3,82 & 1,89 & $10,48 * *$ & 3,62 & 2,20 & 2,37 & 3,09 \\
\hline Horário (H) & 4 & $3,22 *$ & $4,28 * *$ & 0,87 & $2,85^{*}$ & $4,50 * *$ & 1,02 & $3,28 *$ & $3,56^{*}$ & 1,00 \\
\hline$V \times D$ & 1 & 0,47 & $5,21 * *$ & 2,13 & 1,89 & 0,00 & 1,98 & 0,48 & 0,26 & 0,28 \\
\hline $\mathrm{V} \times \mathrm{H}$ & 4 & $2,05^{*}$ & $3,28 *$ & 0,33 & $2,96^{*}$ & $3,34 *$ & 0,31 & 2,09 & 1,95 & 0,63 \\
\hline $\mathrm{D} \times \mathrm{H}$ & 4 & $1,92 *$ & $2,90 *$ & 1,29 & $2,89 *$ & 1,88 & 2,38 & 1,95 & 1,36 & 1,50 \\
\hline Fatorial (F) & 19 & $2,17 *$ & $3,54 * *$ & 1,21 & $2,61 * *$ & $3,42 * *$ & 1,40 & $2,21 *$ & $2,59 * *$ & 1,00 \\
\hline F vs. Tests. & 1 & $44,09 * *$ & $50,61 * *$ & $7,15^{* *}$ & $34,78 * *$ & $15,33 * *$ & $4,50 *$ & $32,37 * *$ & $24,53 * *$ & $4,31 *$ \\
\hline Entre Tests. & 3 & $32,29 * *$ & 0,16 & 1,11 & 2,79 & 0,00 & 1,10 & 2,44 & 0,29 & 0,94 \\
\hline Blocos & 3 & $16,30 * *$ & $8,71 * *$ & 1,41 & $19,09 * *$ & $14,77 * *$ & 0,77 & $16,35 * *$ & $16,28 * *$ & 1,00 \\
\hline $\mathrm{CV}(\%)$ & - & 10,7 & 5,4 & 2,8 & 10,0 & 6,5 & 2,8 & 10,8 & 9,3 & 3,0 \\
\hline Média Geral & - & 52,61 & 81,31 & 92,08 & 52,61 & 83,86 & 95,57 & 52,66 & 70,34 & 95,45 \\
\hline
\end{tabular}

1 Dias após as aplicações.

**, * : valor de $\mathrm{F}$ significativo a 1 e $5 \%$ de probabilidade, respectivamente. 
Tabela 2 - Desdobramentos dos níveis dos fatores estudados para o controle de plantas infestantes na cultura de soja aos 8 e 15 dias após a aplicação. Jaboticabal-SP - 1999

\begin{tabular}{|c|c|c|c|c|c|c|}
\hline \multirow{2}{*}{ Fatores } & \multicolumn{2}{|c|}{ Capim-carrapicho } & \multicolumn{2}{|c|}{ Capim-pé-de-galinha } & \multicolumn{2}{|c|}{ Capim-colchão } \\
\hline & $8^{1}$ & 15 & 8 & 15 & 8 & 15 \\
\hline \multicolumn{7}{|c|}{ Volume } \\
\hline $100 \mathrm{~L} \mathrm{ha}^{-1}$ & $53,1 \mathrm{a}^{2}$ & & $53,1 \mathrm{a}$ & & $52,9 \mathrm{a}$ & $71,2 a$ \\
\hline $200 \mathrm{~L} \mathrm{ha}^{-1}$ & $50,0 \mathrm{~b}$ & & $50,0 \mathrm{~b}$ & & $49,5 \mathrm{~b}$ & $67,2 \mathrm{~b}$ \\
\hline DMS $(5 \%)$ & 2,4 & & 2,4 & & 2,5 & 2,9 \\
\hline \multicolumn{7}{|c|}{ Dosagem } \\
\hline $40 \% \mathrm{D}\left(75,2 \mathrm{~g} \mathrm{ha}^{-1}\right)$ & & & & $81,1 \mathrm{~b}$ & & \\
\hline $60 \% \mathrm{D}\left(112,8 \mathrm{~g} \mathrm{ha}^{-1}\right)$ & & & & $85,1 \mathrm{a}$ & & \\
\hline DMS $(5 \%)$ & & & & 2,5 & & \\
\hline \multicolumn{7}{|c|}{ Horário } \\
\hline $5 \mathrm{~h}$ & $53,7 \mathrm{a}$ & $83,7 \mathrm{a}$ & $53,7 \mathrm{a}$ & $86,9 a$ & $53,7 \mathrm{a}$ & $72,5 \mathrm{a}$ \\
\hline $9 \mathrm{~h}$ & $50,6 a b$ & $81,2 \mathrm{ab}$ & $50,6 a b$ & $85,6 \mathrm{ab}$ & $48,7 \mathrm{ab}$ & $70,3 \mathrm{ab}$ \\
\hline $13 \mathrm{~h}$ & $48,1 \mathrm{~b}$ & $78,1 \mathrm{~b}$ & $48,1 \mathrm{~b}$ & $80,6 \mathrm{~b}$ & $48,2 \mathrm{~b}$ & $67,2 \mathrm{ab}$ \\
\hline $17 \mathrm{~h}$ & $52,4 \mathrm{ab}$ & $79,4 a b$ & $52,5 \mathrm{ab}$ & $81,9 \mathrm{ab}$ & $52,5 \mathrm{ab}$ & $71,2 \mathrm{ab}$ \\
\hline $21 \mathrm{~h}$ & $52,8 \mathrm{ab}$ & $78,7 \mathrm{~b}$ & $52,8 \mathrm{ab}$ & $80,6 \mathrm{~b}$ & $52,8 \mathrm{ab}$ & $65,0 \mathrm{~b}$ \\
\hline DMS (5\%) & 5,2 & 4,4 & 5,2 & 5,5 & 5,6 & 6,5 \\
\hline
\end{tabular}

Dias após as aplicações.

2 Médias seguidas pelas mesmas letras, na coluna e dentro do fator ou contraste, não diferem entre si pelo teste de Tukey $(\mathrm{P}>0,05)$.

Tabela 3 - Desdobramentos das interações significativas entre os fatores estudados para o controle de plantas infestantes na cultura de soja. Jaboticabal-SP - 1999

\begin{tabular}{|c|c|c|c|c|}
\hline \multirow{2}{*}{ Fatores } & \multicolumn{2}{|c|}{ Capim-carrapicho } & \multicolumn{2}{|c|}{ Capim-pé-de-galinha } \\
\hline & $8^{1}$ & 15 & 8 & 15 \\
\hline Volume dentro de & $13 \mathrm{~h}$ & $13 \mathrm{~h}$ & $13 \mathrm{~h}$ & $21 \mathrm{~h}$ \\
\hline $100 \mathrm{Lha}^{-1}$ & $51,2 \mathrm{a}$ & $81,2 \mathrm{a}$ & $51,2 \mathrm{a}$ & $83,7 a$ \\
\hline $200 \mathrm{~L} \mathrm{ha}^{-1}$ & $45,0 \mathrm{~b}$ & $75,0 \mathrm{~b}$ & $45,0 \mathrm{~b}$ & $77,7 \mathrm{~b}$ \\
\hline $\operatorname{DMS}(5 \%)$ & 5,3 & 4,4 & 5,3 & 5,5 \\
\hline Volume dentro de & $21 \mathrm{~h}$ & $60 \% \mathrm{D}$ & $21 \mathrm{~h}$ & \\
\hline $100 \mathrm{~L} \mathrm{ha}^{-1}$ & $56,9 \mathrm{a}$ & $82,7 \mathrm{a}$ & $56,9 \mathrm{a}$ & \\
\hline $200 \mathrm{Lha}^{-1}$ & $48,7 \mathrm{~b}$ & $79,0 \mathrm{~b}$ & $48,7 \mathrm{~b}$ & \\
\hline DMS (5\%) & 5,3 & 2,8 & 5,3 & \\
\hline Dosagem dentro de & $9 \mathbf{h}$ & $5 \mathrm{~h}$ & $9 \mathrm{~h}$ & \\
\hline $40 \% \mathrm{D}$ & $53,7 \mathrm{a}$ & $81,2 \mathrm{~b}$ & $53,7 \mathrm{a}$ & \\
\hline $60 \% \mathrm{D}$ & $47,5 \mathrm{~b}$ & $86,2 \mathrm{a}$ & $47,5 \mathrm{~b}$ & \\
\hline DMS (5\%) & 5,3 & 4,4 & 5,3 & \\
\hline Dosagem dentro de & & $21 \mathrm{~h}$ & & \\
\hline $40 \% \mathrm{D}-3-3$ & & $76,2 \mathrm{~b}$ & & \\
\hline $60 \% \mathrm{D}$ & & $81,2 \mathrm{a}$ & & \\
\hline DMS (5\%) & & 4,4 & & \\
\hline Dosagem dentro de & & $100 \mathrm{~L}$ & & \\
\hline $40 \% \mathrm{D}$ & & $82,7 a$ & & \\
\hline $60 \% \mathrm{D}$ & & $79,2 \mathrm{~b}$ & & \\
\hline DMS (5\%) & & 2,8 & & \\
\hline Horário dentro de & & $60 \% \mathrm{D}$ & & \\
\hline $5 \mathrm{~h} \quad \cdots$ & & $86,2 \mathrm{a}$ & & \\
\hline $9 \mathrm{gh}$ & & $80,0 \mathrm{ab}$ & & \\
\hline $13 \mathrm{~h}$ & & $76,9 \mathrm{~b}$ & & \\
\hline $17 \mathrm{~h}$ & & $80,0 \mathrm{ab}$ & & \\
\hline $21 \mathrm{~h}$ & & $81,2 \mathrm{ab}$ & & \\
\hline DMS (5\%) & & 8,3 & & \\
\hline
\end{tabular}

Dias após as aplicações.

2 Médias seguidas pelas mesmas letras, na coluna e dentro do fator ou contraste, não diferem entre si pelo teste de Tukey $(\mathrm{P}>0,05)$.
Para o fator dosagem reduzida, verifica-se que apenas na avaliação aos 15 dias das aplicações o controle de capim-pé-de-galinha, com aplicação de $60 \%$ da dosagem recomendada (112,8 g de fluazifop-p-butil/ha), foi superior ao proporcionado pela aplicação de $40 \%$ da dosagem recomendada $\left(75,20 \mathrm{~g}^{\text {ha-1 }}{ }^{-1}\right.$. Esses resultados de manutenção da eficiência no controle das plantas daninhas com dosagens reduzidas estão de acordo com os obtidos de Baldwin \& Oliver (1985), Peressin et al. (1993) e Ferreira et al. (1998), em aplicações de diversos herbicidas em pós-emergência na cultura de soja.

No caso do fator horário de aplicação, verifica-se que o controle das três espécies de gramíneas aos 8 e 15 dias após as aplicações foi estatisticamente superior nas aplicações às 5 horas, em relação às aplicações às 13 horas, exceto para o capim-colchão aos 15 dias. Verifica-se também que os demais horários de aplicação não diferiram dos controles avaliados nas aplicações às 5 e 13 horas. As aplicações às 5 horas também proporcionaram controle superior de capim-carrapicho em relação às aplicações às 13 horas com 60\% da dosagem recomendada do fluazifop-p-butil. Esses resultados estão em concordância com os de outros autores (Muzik, 1976; Gazziero \& Fleck, 1980; Friesen \& Wall, 1991; Marochi, 1993). 
Tabela 4 - Resumo da análise de variância com o teste F dos parâmetros avaliados na colheita da cultura de soja. Jaboticabal-SP $-1999$

\begin{tabular}{|c|c|c|c|c|c|c|}
\hline \multirow{2}{*}{ Causas de Variação } & \multirow{2}{*}{ GL } & \multirow{2}{*}{$\begin{array}{l}\text { Número de } \\
\text { plantas/metro } \\
\text { de sulco }\end{array}$} & \multicolumn{2}{|c|}{ Altura média $(\mathrm{cm})$} & \multirow{2}{*}{$\begin{array}{c}\text { Número de } \\
\text { vagens/planta }\end{array}$} & \multirow{2}{*}{$\begin{array}{l}\text { Produção de } \\
\text { grãos }\left(\mathrm{kg} \mathrm{ha}^{-1}\right)\end{array}$} \\
\hline & & & $1^{\mathrm{a}}$ vagem & Plantas & & \\
\hline Volume (V) & 1 & 1,47 & 0,49 & 0,57 & 0,05 & 1,08 \\
\hline Dosagem (D) & 1 & 1,91 & 1,10 & 0,72 & 1,48 & 1,06 \\
\hline Horário (H) & 4 & 0,80 & 1,06 & 0,68 & 0,65 & 0,51 \\
\hline $\mathrm{V} \times \mathrm{D}$ & 1 & 0,88 & $4,43 *$ & 2,12 & 0,69 & 0,27 \\
\hline $\mathrm{Vx} \mathrm{H}$ & 4 & $4,16 * *$ & 0,73 & 1,53 & 1,40 & 1,08 \\
\hline $\mathrm{D} \times \mathrm{H}$ & 4 & 0,59 & 0,84 & 1,51 & 0,46 & 1,47 \\
\hline $\mathrm{V} \times \mathrm{D} \times \mathrm{H}$ & 4 & 0,43 & $2,75^{*}$ & 1,30 & 0,85 & 0,69 \\
\hline Fatorial (F) & 19 & 1,48 & 1,45 & 1,24 & 0,82 & 0,92 \\
\hline F vs. Tests. & 1 & 3,55 & 0,18 & 1,33 & 0,002 & $4,60 *$ \\
\hline Entre Tests. & 3 & 1,68 & 0,33 & 0,39 & 0,25 & 1,47 \\
\hline Blocos & 3 & $8,18 * *$ & $9,74 * *$ & $20,16 * *$ & $13,17 * *$ & $6,99 * *$ \\
\hline $\mathrm{CV}(\%)$ & - & 8,47 & 10,75 & 12,64 & 21,54 & 8,14 \\
\hline Média Geral & - & 18,65 & 15,75 & 69,47 & 26,82 & $2.135,62$ \\
\hline
\end{tabular}

$* *, *$ : valor de $\mathrm{F}$ significativo a 1 e $5 \%$ de probabilidade, respectivamente.

No que se refere ao fator volume de aplicação, verifica-se que as aplicações de $100 \mathrm{~L}$ de calda/ha proporcionaram os melhores controles de capim-carrapicho aos 8 e 15 dias das aplicações às 13 horas e de capim-pé-de-galinha aos 8 dias, às 13 horas, e aos 15 dias, às 21 horas (Tabela 3).

Nas avaliações de intoxicação das plantas de soja realizadas aos 8, 15 e 22 dias após as aplicações, não foram observados sintomas característicos nas folhas que pudessem ser devidos às aplicações do herbicida fluazifop-pbutil, conforme descrições de Vidal (1997). Portanto, foi atribuída a nota 1 a todas as parcelas experimentais, de acordo com a escala de notas do EWRC (1964).

Os resultados das análises de variância dos parâmetros avaliados, relativos às plantas e à cultura de soja, estão contidos na Tabela 4. Verifica-se, nesses dados, que os três fatores isolados não proporcionaram efeitos significativos sobre as plantas e a cultura de soja. Foram observados efeitos significativos das interações do volume de aplicação dentro de horários apenas para o número de plantas por metro linear de sulco, na época da colheita.
Houve efeito significativo também do volume de aplicação dentro da dosagem na altura de inserção da $1^{\underline{a}}$ vagem, ou da vagem mais baixa. Houve diferença significativa no contraste entre o fatorial e as testemunhas.

Não obstante esses efeitos significativos, em que todos foram em nivel de $5 \%$ de probabilidade, exceto entre volume e dosagem para o número de planta de soja por metro linear de sulco, as diferenças das médias dos tratamentos não foram detectadas pelo teste de Tukey (Tabela 4). Assim, verifica-se, pelos resultados da Tabela 4 , que o herbicida fluazifop-p-butil manteve-se totalmente seletivo para as plantas e a cultura de soja, independentemente dos tratamentos testados, inclusive no esquema fatorial. Portanto, estão de acordo com todos os trabalhos citados anteriormente que objetivaram otimizar as aplicações de herbicidas em pós-emergência.

Os valores médios dos parâmetros avaliados nas plantas de soja e na cultura, em cada nível dos três fatores testados e das testemunhas, estão apresentados na Tabela 5. Considerando as testemunhas sem aplicação, verifica-se que as plantas infestantes reduziram 
em $12 \%$ a produção de grãos da cultura. Esse resultado é inferior aos verificados em outros trabalhos (Marochi, 1993), devido às excelentes condições climáticas observadas durante o ciclo da cultura, conforme se observa na Figura 3. Portanto, neste experimento ocorreu pequena competição entre as plantas infestantes e as de soja pelos fatores de produção, principalmente água, pois durante o ciclo da cultura ocorreram $1.339,3 \mathrm{~mm}$ de chuva na área experimental (Figura 2).

Embora não tenha havido nenhum efeito significativo dos tratamentos, constata-se que as aplicações do herbicida fluazifop-p-butil com volume de $100 \mathrm{~L}$ de calda/ha e com até $60 \%$ de redução na dosagem foram tão eficientes quanto a dosagem recomendada. Esse resultado possibilita aumentar significativamente a capacidade operacional da aplicação, bem como reduzir o custo do herbicida, resultando em grande economia para o agricultor em sua necessidade de controle químico das plantas daninhas, concordando com Marochi (1993). Portanto, com esses resultados, fica demonstrada a possibilidade de otimização da aplicação do herbicida fluazifop-p-butil na cultura de soja, para o controle de gramíneas anuais.

\section{LITERATURA CITADA}

ALAM. Asociación Latinoamericana de Malezas. Recomendaciones sobre unificación de los sistemas de evolucion en ensayos de control de malezas. Bogotá, 1974. v.1, p.35-38.

BALDWIN, F.L.; OLIVER, L.R. A reduced rate intensive management soybean weed control program. In: SOUTHERN WEED SCIENCE SOCIETY, 38, 1985, Gainesville. Proceeding... Gainesville: SWSS, 1985. p.487.

DEVLIN, D.L.; LONG, J.H.; MADDUX, L.D. Using reduced rates of postemergence herbicides in soybeans (Glycine max). Weed Technol., v.5, n.4, p.834-840, 1991.

DURIGAN, J.C.; VICTÓRIA FILHO, R. Comportamento de baixas doses de herbicidas na cultura da soja [Glycine max (L.) Merrill]. IEfeitos sobre o controle das plantas infestantes e parâmetros de produção da cultura. Planta Infest., v.6, n.1, p.39-50, 1983.

EUROPEAN WEED RESEARCH COUNCIL. Report of the $3^{\text {rd }}$ and 4 th meetings of EWRC. Committee of methods in weed research. Weed Res., v.4, n. 1, p.88, 1964.

Tabela 5 - Valores médios dos parâmetros avaliados nas plantas de soja e na cultura para cada nível dos três fatores testados e das testemunhas. Jaboticabal-SP - 1999

\begin{tabular}{|c|c|c|c|c|c|}
\hline \multirow{2}{*}{ Fatores } & \multirow{2}{*}{$\begin{array}{c}\text { Número de } \\
\text { plantas/metro de } \\
\text { sulco }\end{array}$} & \multicolumn{2}{|c|}{ Altura média (cm) } & \multirow{2}{*}{$\begin{array}{c}\text { Número de } \\
\text { vagens/planta }\end{array}$} & \multirow{2}{*}{$\begin{array}{l}\text { Produção de } \\
\text { grãos }\left(\mathrm{kg} \mathrm{ha}^{-1}\right)\end{array}$} \\
\hline & & $1^{\mathrm{a}}$ vagem & Plantas & & \\
\hline \multicolumn{6}{|c|}{ Volume (V) } \\
\hline $100 \mathrm{~L} \mathrm{ha}^{-1}$ & 18,6 & 15,8 & 68,3 & 27,0 & $2.132,4$ \\
\hline $200 \mathrm{~L} \mathrm{ha}^{-1}$ & 19,0 & 15,6 & 69,7 & 26,7 & $2.172,8$ \\
\hline \multicolumn{6}{|c|}{ Dosagem (D)15,9 } \\
\hline $40 \% \mathrm{D}\left(75,2 \mathrm{~g} \mathrm{ha}^{-1}\right)$ & 19,1 & 15,9 & 68,2 & 26,0 & $2.132,6$ \\
\hline $60 \% \mathrm{D}\left(112,8 \mathrm{~g} \mathrm{ha}^{-1}\right)$ & 18,5 & 15,5 & 69,8 & 27,6 & $2.172,6$ \\
\hline \multicolumn{6}{|c|}{ Horário $(\mathbf{H})$} \\
\hline $5 \mathrm{~h}$ & 18,8 & 15,8 & 65,9 & 26,5 & $2.107,7$ \\
\hline $9 \mathrm{~h}$ & 18,3 & 14,9 & 70,0 & 26,1 & $2.140,8$ \\
\hline $13 \mathrm{~h}$ & 19,2 & 15,9 & 70,5 & 27,1 & $2.106,0$ \\
\hline $17 \mathrm{~h}$ & 18,5 & 15,9 & 69,5 & 25,7 & $2.140,7$ \\
\hline $21 \mathrm{~h}$ & 19,0 & 16,0 & 69,0 & 28,7 & $2.107,7$ \\
\hline Testemunha capinada & 17,0 & 16,5 & 69,3 & 25,8 & $2.159,7$ \\
\hline Test. sem capina & 17,5 & 15,8 & 73,5 & 29,0 & $1.901,5$ \\
\hline Test. $188 \mathrm{~g} / 100 \mathrm{~L} \mathrm{ha}^{-1}$ & 19,4 & 15,9 & 74,7 & 25,9 & $2.146,6$ \\
\hline Test. $188 \mathrm{~g} / 200 \mathrm{~L} \mathrm{ha}^{-1}$ & 17,9 & 15,3 & 69,6 & 26,8 & $2.093,9$ \\
\hline
\end{tabular}


FERREIRA, M.C.; MACHADO NETO, J.G.; MATUO, T. Redução da dose e do volume de calda nas aplicações noturnas de herbicidas em pósemergência na cultura de soja. Planta Daninha. v.16, n.1, p.25-36, 1998.

FRIESEN, G.H.; WALL, D.A. Effect of apllication factors on efficacy of fluazifop-p-butyl in flax. Weed Techon., v.5, p.504-508, 1991.

GAZZIERO, D.L.P.; FLECK, N.G. Efeitos de três herbicidas pós-emergentes aplicados em diferentes horas do dia sobre ervas daninhas e plantas de soja [Glycine max (L.) Merrill]. Planta Daninha, v.3, n.1, p.23-29, 1980.

KING, C.A.; OLIVER, L.R. Application rate and timing of acifluorfen, bentazon, chlorimuron and imazaquin. Weed Technol., v.6, n.3, p.526-534, 1992.

MAROCHI, A.I. Tecnologia de aplicação de defensivos agrícolas. In: SIMPÓSIO INTERNACIONAL SOBRE SEMEADURA DIRETA EM SISTEMAS SUSTENTÁVEIS, 1993, Castro. Anais ... Castro: Fundação A.B.C, 1993. p. 208227.
MUZIK, T.J. Influence of environmental factors on toxicity to plants. In: AUDUS, L.J. Herbicides: physiology, biochemistry and ecology. 2.ed. London, Academic Press, 1976. v.2, p.203-47.

PERESSIN, V.A.; FILHO, R.V.; PERECIN, D. Efeitos de doses e épocas de aplicação de misturas de herbicidas no controle de plantas infestantes na cultura da soja. In: CONGRESSO BRASILEIRO DE HERBICIDAS E PLANTAS DANINHAS, 19, 1993, Londrina. Resumos... Londrina: 1993. p.112-113.

PIMENTEL-GOMES, F. Curso de estatística experimental. 10.ed. Piracicaba: Nobel, 1982. 430p.

RODRIGUES, B.N.; ALMEIDA, F.L.S. Guia de herbicidas. 3.ed. Londrina: Livroceres, 1995. $675 p$.

SOUZA, R.O.; DORNELLES, S.H.B. Influência do volume de calda na mistura de herbicidas pósemergentes na soja (Glycine max (L.) Merril). In: CONGRESSO BRASILEIRO DE HERBICIDAS E PLANTAS DANINHAS, 20, 1995, Florianópolis. Palestras...Florianópolis: 1995. p.41.

VIDAL, R.A. Herbicidas: mecanismos de ação e resistência de plantas. Rio Grande do Sul, UFRGS, 1997. 165p. 